\title{
Keakraban dalam Persahabatan dan Corak Interaksi di Media Sosial
}

\author{
NUR HAFEEZA AHMAD PAZIL \\ Universiti Sains Malaysia
}

\begin{abstract}
ABSTRAK
Menerusi peluang penajaan daripada kerajaan, syarikat swasta atau agensi tertentu, pelajar-pelajar cemerlang di Malaysia berpeluang untuk belajar di universiti ternama dan tinggal di luar negara dalam tempoh tiga hingga lima tahun untuk melengkapkan pengajian mereka. Mobiliti sementara untuk meneruskan pengajian ke peringkat tinggi di luar negara telah menimbulkan pelbagai cabaran kepada pelajar-pelajar Malaysia yang perlu hidup bersendirian dalam persekitaran yang asing pada usia yang agak muda. Selain cabaran untuk beradaptasi di negara yang berbeza latar belakang budaya, pelajar-pelajar ini juga berhadapan dengan cabaran untuk mengekalkan hubungan akrab dengan sahabat dan keluarga yang berada jauh secara fizikal dari mereka. Persoalannya di sini adakah mobiliti geografi ini mempengaruhi amalan intimasi dalam persahabatan akrab dan adakah media sosial membantu untuk mendekatkan jarak fizikal antara pelajar dan sahabat akrab mereka di Malaysia? Menerusi penulisan diari persahabatan selama tiga minggu, peta persahabatan dan temu bual mendalam, interaksi lapan orang pelajar Malaysia dengan sahabat akrab mereka telah direkodkan dan dianalisa. Artikel ini membincangkan sejauh mana media sosial membantu untuk mengukuhkan atau melemahkan amalan intimasi dalam persahabatan akrab bagi pelajar Malaysia yang berhijrah ke United Kingdom dengan meneliti corak interaksi mereka. Empat corak interaksi yang telah dikenal pasti adalah: 1) penambahan atau penyingkiran nama sahabat akrab, 2) kekerapan hubungan, 3) tempoh dan medium interaksi, dan 4) kandungan interaksi.
\end{abstract}

Kata kunci: Persahabatan akrab, intimasi, corak interaksi, mobiliti, media sosial.

\section{Intimacy in Friendship and Style of Interaction on Social Media}

\begin{abstract}
Sponsorship opportunities from governments, private companies or agencies enable excellent students in Malaysia to study at reputable universities and stay abroad for three to five years to complete their studies. Temporarily mobility for study while living abroad poses challenges for international students who must survive alone in unfamiliar surroundings at a relatively young age. Besides the challenges for adaptation of living in a country with different cultural backgrounds, these students also face the challenges of maintaining close relationships with friends and family who are physically distant. This has raised a question of whether geographical mobility influences the practices of intimacy in the close friendship of Malaysian students and does social media help to blur the distance between the students and their friends in Malaysia? By using three-weeks friendship diary, friendship maps and in-depth interviews, the interaction of 8 Malaysian students with their close friends was recorded and analyzed. This article discusses the extent to which social media help to strengthen or weaken the intimacy practices in close friendships for Malaysian students living in the United Kingdom by examining their interaction patterns. The four identified patterns of interaction are 1) the addition or removal of close friends' names, 2) the frequency of contact, 3) the length of interaction and 4) the content of the interaction.
\end{abstract}

Keywords: Close friendships, intimacy, interaction patterns, mobility, social media. 


\section{PENGENALAN}

Terdapat anggapan bahawa apabila seseorang berpindah ke lokasi geografi yang berlainan, hubungan peribadi mereka, khususnya hubungan persahabatan akan menjadi renggang. Walau bagaimanapun, penemuan dalam kajian ini menunjukkan bahawa jarak, masa dan ruang fizikal bukan hanya dilihat sebagai kekangan tetapi dalam masa yang sama membantu dalam mengukuhkan dan membina persahabatan yang erat. Kajian ini mengenal pasti perubahan dari segi amalan, penggunaan media dan rutin interaksi intim disebabkan oleh mobiliti sementara ke luar negara bagi pelajar Malaysia di United Kingdom. Amalan intimasi menerusi media sosial dilihat sebagai salah satu platform penting untuk interaksi. Media sosial menjadi sangat signifikan dalam konteks mobiliti ke luar negara kerana tinggal berjauhan menyebabkan kesukaran untuk pelajar di United Kingdom bertemu dengan keluarga dan rakan-rakan akibat kos yang tinggi untuk pulang ke Malaysia secara kerap. Artikel ini membincangkan mengenai bagaimana jarak fizikal telah mengubah cara pelajar Malaysia berinteraksi dengan sahabat akrab yang tinggal berjauhan dan berdekatan dengan mereka. Pengkaji mendapati bahawa media sosial digunakan untuk menggantikan serta memulakan interaksi bersemuka. Walau bagaimanapun, jarak fizikal telah membawa amalan intimasi yang baharu terutamanya dalam konteks interaksi secara maya.

Dalam artikel ini, dua hujah utama ditonjolkan untuk memahami amalan intimasi dalam persahabatan akrab pelajar Malaysia di United Kingdom. Pertama, jarak fizikal telah membentuk corak interaksi baru antara pelajar dan sahabat akrab mereka. Media sosial memainkan peranan penting, terutamanya dalam persahabatan akrab jarak jauh. Kebanyakan interaksi berlaku secara maya terutamanya menerusi teks mesej serta panggilan suara dan video sebagai pengganti interaksi secara bersemuka antara pelajar dengan sahabat akrab yang tinggal berjauhan. Malah, media sosial juga menjadi platform permulaan untuk interaksi bersemuka dengan sahabat akrab yang tinggal berdekatan. Kedua, penggunaan media sosial untuk berinteraksi dengan sahabat akrab yang tinggal berjauhan dan sahabat akrab yang tinggal berdekatan memperlihat cara pelajar-pelajar Malaysia mengamalkan intimasi dalam persahabatan akrab mereka. Oleh itu, artikel ini membincangkan empat corak interaksi antara pelajar-pelajar ini dengan sahabat akrab mereka dan mengetahui bagaimana media sosial mempengaruhi amalan intimasi dalam persahabatan akrab berdasarkan konteks mobiliti sementara ke luar negara.

\section{Media Sosial dan Hubungan Persahabatan}

\section{SOROTAN KARYA}

Penggunaan media sosial telah tertanam dalam rutin dan gaya hidup masyarakat pada hari ini dan kajian mendapati bahawa belia merupakan pengguna yang paling kerap mengakses e-mel, media sosial dan teks mesej (Boyd, 2010; Chambers, 2013). Pengkaji berpendapat bahawa media sosial bukan sahaja membenarkan pengguna untuk mengkonstruksi dan memaparkan identiti kepada awam seperti yang dimahukan (Jamilah et al., 2019) malah, media sosial juga menyediakan alat untuk membina rangkaian yang signifikan dalam mewujudkan persahabatan baharu dan dalam masa yang sama mengekalkan hubungan peribadi sedia ada. Sebagai medium interaksi sosial dan perkongsian maklumat, pengkaji tertarik dengan persoalan bagaimana interaksi maya di media sosial menghasilkan corak amalan intimasi tertentu dan kemudiannya bercampur dengan interaksi bersemuka.

Menurut Davies (2011), media sosial bertindak sebagai tambahan atau pelengkap untuk cara interaksi sosial yang sedia ada - interaksi bersemuka, surat dan panggilan telefon konvensional - untuk pengguna menyedari dan menguruskan hubungan peribadi mereka. 
Pengkaji mendapati bahawa media sosial telah mencipta amalan intimasi yang baharu dalam interaksi sosial. Selain itu, peranan sosial, status sosial dan lokasi struktural tidak mempunyai kesan yang signifikan terhadap pembentukan dan amalan persahabatan di media sosial. Media sosial membenarkan pengguna untuk membentuk persahabatan, berinteraksi dan melakukan persahabatan tanpa memerlukan interaksi bersemuka dan tanpa sempadan sosial dan fizikal. Media sosial membolehkan pengguna untuk mengekalkan sahabat yang sedia ada, berkawan dengan orang yang tidak dikenali yang berkongsi minat yang sama, mencari rakan yang tinggal berjauhan atau rakan yang sudah lama tidak dihubungi, serta berpeluang untuk mengenali rakan sekerja, sebagai contoh, dengan lebih rapat apabila mereka tersenarai sebagai sahabat di media sosial (Boyd, 2010). Walau bagaimanapun, seperti yang dihujahkan oleh Boyd (2010) dan Davies (2011), pengguna perlu mempunyai sambungan internet dan masing-masing bersetuju untuk menjadi sahabat dengan menerima permintaan untuk menjadi sahabat di media sosial.

Media sosial juga membentuk satu etika baharu dalam amalan persahabatan, dan dalam masa yang sama menunjukkan cara pengurusan persahabatan sedia ada dan cara untuk menangani sahabat yang tidak diingini (Holmes, 2011; Jamieson, 2013; McLaughlin \& Vitak, 2011). Boyd (2010) berhujah bahawa media sosial membolehkan pengguna untuk menyambung, membina dan menguruskan rakan-rakan mereka dengan proses perundingan amalan dan norma sosial. Pengguna media sosial kebiasaannya mengikuti satu set amalan sosial mengenai 'sahabat' yang diterima oleh komuniti dalam talian. Hal ini disebabkan oleh pengguna media sosial kini boleh mengkategorikan jenis persahabatan mereka di media sosial dan menghormati perbezaan tersebut, serta mempunyai batasan jangkaan yang jelas dalam persahabatan seperti yang dihujahkan oleh Pahl (2000). Pengguna dilihat mempunyai kategori hubungan persahabatan yang berlainan di media sosial yang bergantung pada minat dan aktiviti tertentu, dan keakraban persahabatan dapat diukur berdasarkan kualiti kandungan dan kekerapan interaksi mereka di media sosial (Boyd, 2010). Malah, Siti Ezaleila (2016) mendapati bahawa media sosial membenarkan pengguna untuk meluaskan persahabatan mereka dan dalam masa yang sama mengakhiri persahabatan yang tidak menyenangkan.

Walau bagaimanapun, Hall dan Baym (2011) menunjukkan bahawa interaksi berlebihan di media sosial boleh meningkatkan jangkaan dan kebergantungan dalam persahabatan yang juga mencetuskan rasa tidak puas hati dalam persahabatan tersebut. Tambahan pula, persahabatan jarak jauh berhadapan dengan jangkaan yang lebih tinggi dan salah faham. Cantó-Milà et al. (2016) berhujah bahawa interaksi maya telah menjadi sebahagian daripada 'imaginasi impian'. Pengguna membayangkan reaksi penerima teks mesej yang dihantar dan membayangkan bahawa penerima teks mesej tersebut wujud secara ideal, berminat dan peduli dengan perkara yang mereka sampaikan menerusi mesej tersebut. Namun, media sosial sebenarnya telah mengubah jangkaan amalan intimasi dan mewujudkan tekanan dalam interaksi (Jurkane-Hobein, 2015). Menurut Jamieson (2013), teknologi baharu ini telah membawa beban dan tekanan baharu terhadap jangkaan dalam persahabatan. Hal ini disebabkan oleh seseorang akan dianggap tidak berminat untuk berinteraksi jika mereka tidak memberi respon yang sesuai dengan status yang dikemaskini oleh sahabat mereka di media sosial. 
Menghubungkan yang Jauh dan Mendekatkan yang Dekat

Spencer dan Pahl (2006) mengakui bahawa kebanyakan kajian mengenai persahabatan dan teknologi komunikasi adalah tertumpu pada kekuatan persahabatan. Pengguna kebiasaannya menggunakan panggilan telefon dan khidmat pesanan ringkas (SMS) untuk mendapatkan maklum balas serta-merta daripada sahabat akrab mengenai aktiviti harian atau perkara peribadi (Taylor \& Harper, 2003), menggunakan chatroom dan dating sites untuk mencari pasangan dan sahabat baharu (Brickell, 2012), dan menggunakan e-mel untuk interaksi rasmi dan untuk berhubung dengan sahabat yang tinggal berjauhan. Pengguna lebih cenderung untuk menggunakan media sosial berbanding panggilan telefon untuk berhubung dengan sahabat dan keluarga mereka apabila tinggal berjauhan. Pertemuan bersemuka, berkongsi ruang fizikal yang sama dan menghabiskan masa bersama adalah antara cabaran besar dalam persahabatan jarak jauh (Cronin, 2014; Policarpo, 2016).

Tinggal berjauhan menyebabkan perbualan bersemuka dan secara langsung terhalang. Namun, media sosial membenarkan interaksi bersemuka menerusi panggilan video sama ada di Facebook, Skype atau aplikasi media sosial lain yang membenarkan fungsi ini. Sandel (2014) mendapati bahawa Skype dan panggilan video yang lain menimbulkan rasa kesegeraan dan membantu untuk mengecilkan jarak fizikal yang mampu mengurangkan tekanan dan perasaan rindu yang timbul apabila berada bersendirian dan jauh dari rumah. Media sosial membenarkan pengguna untuk menghubungi mereka yang tinggal berjauhan sekaligus mengurangkan rasa kesepian (Ali \& Siti Minanda, 2017). Malah, Chambers (2013) berhujah bahawa panggilan video memberikan 'ilusi kehadiran bersama' kerana pengguna seolah-olah turut sama menyertai aktiviti yang berlangsung. Media sosial memberi peluang kepada pengguna untuk merasakan kehadiran dan sokongan sosial walaupun mereka dipisahkan oleh jarak fizikal. Menerusi panggilan suara, panggilan video dan penghantaran mesej yang percuma, pengguna media sosial yang tinggal berjauhan boleh berhubung dengan sahabat dan keluarga pada bila-bila masa selagi mereka mempunyai sambungan internet.

Media sosial juga adalah penting dalam proses penyesuaian hidup sewaktu mobiliti sementara ke luar negara. Pengkaji bersetuju dengan hasil kajian oleh Abdul Latiff et al. (2014), yang mendapati bahawa internet dan media sosial membantu pelajar Malaysia sebelum ke luar negara, membantu pelajar mengenali universiti, tempat dan pengangkutan tempatan, serta membentuk hubungan persahabatan dengan pelajar Malaysia yang lain di sana. Selain itu, Abdul Latiff et al. (2014) berhujah bahawa dengan kemajuan teknologi, pelajar Malaysia kadang-kadang merasa seperti mereka tidak meninggalkan tanah air dan norma budaya walaupun mereka sebenarnya tinggal di luar negara. Media sosial membolehkan interaksi bersemuka secara maya yang membantu para pelajar untuk terus berhubung dengan keluarga dan rakan-rakan di Malaysia, serta mendapatkan maklumat terkini mengenai berita dan hiburan di Malaysia.

Walau bagaimanapun, Sandel (2014) mendapati bahawa pelajar lebih mudah untuk beradaptasi dengan kehidupan di luar negara sekiranya mereka tidak melayari internet dan berinteraksi di media sosial dengan keluarga dan rakan-rakan di rumah. Hal ini menyebabkan wujudnya persoalan sama ada seseorang itu benar-benar meninggalkan negara mereka apabila tinggal di luar negara seperti yang dibangkitkan oleh Abdul Latiff et al. (2014) dan sama ada media sosial membantu atau menghalang proses penyesuaian hidup di luar negeri, seperti yang diperkatakan oleh Sandel (2014). 


\section{METODOLOGI}

Kajian ini memfokuskan pada corak interaksi pelajar-pelajar Malaysia di UK dan amalan intimasi dalam persahabatan akrab. Bahagian metodologi ini menerangkan proses pengumpulan data dan latar belakang kajian, termasuklah profil demografi pelajar yang mengambil bahagian. Lapan orang pelajar Malaysia yang tinggal di Barat Laut England, United Kingdom melebihi satu tahun, berusia antara 20 hingga 25 tahun telah dipilih dalam kajian ini. Tujuan kajian ini memberi tumpuan pada satu kumpulan peserta yang berkongsi kumpulan umur dan latar belakang yang sama adalah untuk memahami corak tingkah laku yang diharapkan dan diterima berdasarkan satu latar belakang budaya.

Terdapat dua fasa pengumpulan data dalam kajian ini. Pertama, informan diminta untuk menyenaraikan sahabat akrab tidak melebihi 20 orang dan mereka perlu melengkapkan peta persahabatan dengan menyusun nama sahabat akrab tersebut dalam lingkaran peta persahabatan seperti dalam Rajah 1 mengikut darjah keakraban mereka. Berdasarkan peta persahabatan ini, temubual secara mendalam dilakukan secara tertutup dalam persekitaran tidak formal. Bahasa Inggeris dan bahasa Melayu digunakan untuk temu bual. Semua nama yang dilaporkan dalam kajian ini, termasuk nama informan dan sahabat akrab mereka diubah untuk mengekalkan kerahsiaan. Informan menggunakan kod nama seperti, F1 dan F2, dalam peta persahabatan dan temubual untuk merujuk pada sahabat akrab mereka, dan tidak menggunakan nama sebenar. Pengkaji juga bertanya kepada informan mengenai pengalaman dan tanggapan mereka tentang persahabatan akrab, butiran nama termasuk akrab dan sebab pemilihan senarai nama tersebut. Matlamat kajian ini adalah untuk mendapatkan perspektif yang luas mengenai persahabatan akrab dan interaksi intim antara pelajar-pelajar Malaysia dengan sahabat akrab yang tinggal berjauhan dan berdekatan.

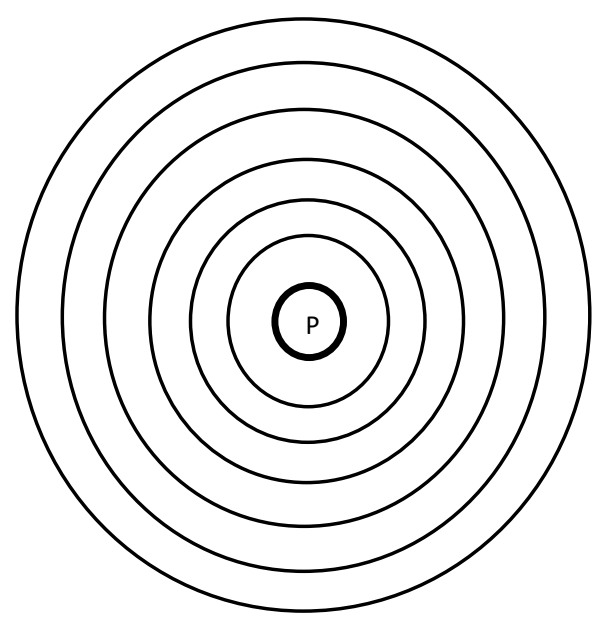

Rajah 1: Peta Persahabatan

Kedua, informan ditemu bual untuk kali kedua selepas tiga minggu. Dalam tempoh tiga minggu selepas temu bual pertama, informan diminta untuk merekodkan interaksi mereka sama ada secara bersemuka atau secara maya bersama dengan sahabat akrab mereka dalam diari persahabatan. Dalam temu bual kedua ini, informan diminta untuk menyenaraikan dan menyusun nama sahabat akrab mereka dalam peta persahabatan yang kedua dan pengkaji akan menemubual informan berdasarkan diari persahabatan yang telah direkodkan. 
Informan kajian ini terdiri daripada lapan orang pelajar Malaysia iaitu empat orang pelajar lelaki dan empat orang pelajar lelaki perempuan, di tiga buah universiti di Barat Laut England, United Kingdom. Semua informan belum berkahwin dan datang ke United Kingdom tanpa ahli keluarga. Hampir semua informan datang ke United Kingdom buat kali pertama dengan tujuan untuk menyambung pengajian di peringkat sarjana muda. Pengkaji memilih pelajar Malaysia sebagai informan kajian bukan hanya disebabkan oleh pengkaji merupakan rakyat Malaysia tetapi juga disebabkan oleh bilangan masyarakat Malaysia yang tinggal di United Kingdom adalah tinggi iaitu kira-kira 60,000 orang seperti yang dilaporkan dalam bancian di United Kingdom (Office for National Statistics, 2017). Selain itu, Malaysia adalah salah satu daripada negara-negara bukan EU yang sering menghantar pelajar untuk pendidikan tinggi di United Kingdom (UKCISA, 2019). Informan yang menepati ciri-ciri yang diinginkan telah dikenal pasti dan dengan menggunakan kaedah persampelan snowball, pengkaji mendapatkan bantuan daripada informan tersebut untuk mencari informan lain yang berkongsi ciri-ciri yang serupa. Mobiliti sementara ke luar negara merupakan tumpuan dalam kajian ini, maka pemilihan informan hanya tertakluk pada pelajar yang telah tinggal di United Kingdom melebihi satu tahun.

\section{HASIL KAJIAN DAN PERBINCANGAN}

Jarak fizikal menjadi faktor utama yang mempengaruhi cara pelajar Malaysia berinteraksi dengan sahabat akrab yang tinggal berjauhan dan berdekatan. Bahagian ini membincangkan corak interaksi dan mengenal pasti persamaan dan perbezaan dalam amalan keintiman pelajar lelaki dan perempuan berdasarkan interaksi maya mereka menerusi media sosial dan interaksi bersemuka. Corak interaksi diringkaskan dalam Jadual 1 dan 2. Empat pelajar lelaki: Ken, Alvin, Adam dan Alif dan empat pelajar wanita: Yana, Aina, Lily dan Mila telah merekodkan interaksi mereka dengan sahabat akrab dalam diari persahabatan selama tiga minggu. Terdapat empat corak interaksi yang diperolehi menerusi kajian ini iaitu: 1) penambahan atau penyingkiran nama sahabat akrab, 2) kekerapan interaksi, 3) tempoh dan medium interaksi, dan 4) kandungan interaksi. Persoalan yang dibangkitkan di sini adalah mengapakah terdapat perbezaan dalam amalan intimasi dengan sahabat yang tinggal berjauhan dengan sahabat yang tinggal berdekatan? 


\begin{tabular}{|c|c|c|c|c|c|c|c|c|c|c|c|c|c|c|}
\hline \multirow[t]{2}{*}{ Gender } & \multirow[t]{2}{*}{ Nama } & \multirow[t]{2}{*}{$\begin{array}{c}\text { Bil. } \\
\text { sahabat } \\
\text { akrab }\end{array}$} & \multirow{2}{*}{$\begin{array}{l}\text { Bil. } \\
\text { sahabat } \\
\text { akrab } \\
\text { baharu }\end{array}$} & \multicolumn{2}{|c|}{$\begin{array}{l}\text { Penambahan atau } \\
\text { penyingkiran nama } \\
\text { sahabat akrab }\end{array}$} & \multicolumn{2}{|c|}{$\begin{array}{l}\text { Kekerapan interaksi } \\
\text { (untuk tiga minggu) }\end{array}$} & \multicolumn{3}{|c|}{ Tempoh interaksi } & \multicolumn{4}{|c|}{ Medium Interaksi } \\
\hline & & & & $\begin{array}{l}\text { Sahabat } \\
\text { jauh }\end{array}$ & $\begin{array}{c}\text { Sahabat } \\
\text { dekat }\end{array}$ & $\begin{array}{l}\text { Sahabat } \\
\text { jauh }\end{array}$ & $\begin{array}{c}\text { Sahabat } \\
\text { dekat }\end{array}$ & $\begin{array}{l}1-30 \\
\text { minit }\end{array}$ & $\begin{array}{l}<1 \\
j a m\end{array}$ & $\begin{array}{l}>1 \\
\text { jam }\end{array}$ & Bersemuka & $\begin{array}{l}\text { WhatsApp/ } \\
\text { Mesej/SMS }\end{array}$ & $\begin{array}{c}\text { Panggilan } \\
\text { suara/video }\end{array}$ & $\begin{array}{l}\text { Facebook/ } \\
\text { Instagram }\end{array}$ \\
\hline \multirow{4}{*}{ 妾 } & Ken & 20 & 18 & +1 & $-7(+4)$ & 1 & 20 & 9 & 5 & 7 & 19 & 2 & 0 & 0 \\
\hline & Alvin & 20 & 13 & -9 & $-3(+5)$ & 0 & 36 & 3 & 1 & 32 & 30 & 19 & 3 & 1 \\
\hline & Adam & 18 & 18 & 0 & 0 & 18 & 2 & 0 & 18 & 2 & 2 & 18 & 0 & 0 \\
\hline & Alif & 17 & 14 & $-3(+3)$ & -3 & 16 & 25 & 17 & 11 & 13 & 38 & 8 & 4 & 0 \\
\hline \multirow{4}{*}{ 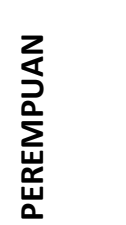 } & Yana & 13 & 14 & -3 & +4 & 16 & 42 & 24 & 4 & 30 & 36 & 20 & 1 & 8 \\
\hline & Aina & 20 & 21 & 0 & +1 & 40 & 14 & 48 & 1 & 5 & 14 & 36 & 3 & 1 \\
\hline & Lily & 14 & 14 & 0 & 0 & 33 & 31 & 51 & 5 & 8 & 26 & 23 & 7 & 8 \\
\hline & Mila & 20 & 16 & -4 & 0 & 42 & 8 & 25 & 2 & 23 & 18 & 38 & 15 & 1 \\
\hline
\end{tabular}

\begin{tabular}{|c|c|c|c|c|c|c|c|c|c|c|c|c|c|c|c|c|}
\hline \multirow[t]{2}{*}{ Gender } & \multirow[t]{2}{*}{ Nama } & \multicolumn{3}{|c|}{ Individu yang memulakan interaksi } & \multicolumn{12}{|c|}{ Kandungan Interaksi } \\
\hline & & $\begin{array}{l}5 \\
\vdots \\
\vdots \\
\vdots \\
\vdots\end{array}$ & 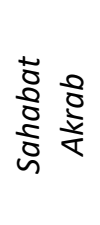 & \begin{tabular}{l}
0 \\
\multirow{2}{0}{} \\
0 \\
$\vdots$ \\
0 \\
0 \\
0 \\
$\dot{0}$
\end{tabular} & 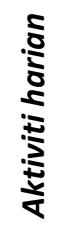 & 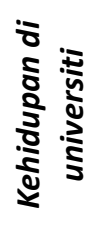 & $\begin{array}{l}\frac{5}{\delta} \\
\frac{5}{5} \\
\frac{\delta}{1}\end{array}$ & $\begin{array}{l}\frac{5}{0} \\
\frac{0}{0} \\
0\end{array}$ & 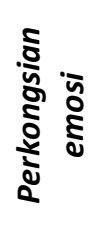 & 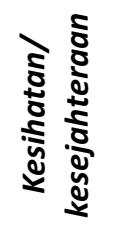 & 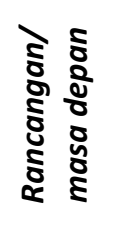 & 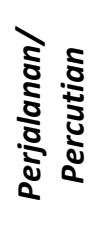 & 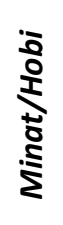 & 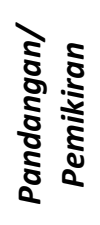 & 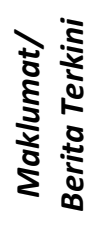 & 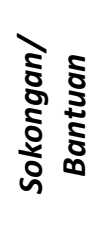 \\
\hline \multirow{4}{*}{ 妾 } & Ken & 16 & 5 & 0 & / & / & & / & / & & / & & & & & \\
\hline & Alvin & 13 & 15 & 8 & / & / & & / & & & / & & / & & / & \\
\hline & Adam & 2 & 9 & 9 & l & / & & / & & & & / & / & & & \\
\hline & Alif & 16 & 25 & 0 & / & / & & / & / & & / & & / & / & & \\
\hline \multirow{4}{*}{ 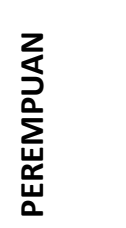 } & Yana & 16 & 32 & 10 & / & / & / & / & & / & / & / & / & & / & \\
\hline & Aina & 13 & 18 & 0 & I & / & / & I & / & / & & & / & / & / & / \\
\hline & Lily & 26 & 38 & 0 & I & I & I & I & I & / & / & & I & & / & / \\
\hline & Mila & 18 & 7 & 9 & I & I & & I & / & / & / & & & & & \\
\hline
\end{tabular}




\section{a) Penambahan atau Penyingkiran Nama Sahabat Akrab}

Jadual 1 menunjukkan perubahan dalam bilangan sahabat akrab selepas tiga minggu. Setelah informan selesai melengkapkan diari persahabatan selama tiga minggu, pengkaji telah melakukan temubual mendalam dan meminta mereka menyenaraikan nama sahabat akrab dan menyusunnya pada peta persahabatan yang kedua. Informan dibenarkan memasukkan atau mengeluarkan nama yang telah tersenarai di peta persahabatan pertama semasa fasa pertama pengumpulan data, serta nama-nama baharu yang telah direkodkan dalam diari persahabatan mereka. Pengkaji telah membandingkan peta persahabatan pertama dan kedua dan bertanya kepada informan mengenai perubahan dari segi kedudukan nama dan nama-nama sahabat akrab yang telah ditambah atau dibuang.

Pengkaji mendapati bahawa separuh daripada informan menambah sekurangkurangnya seorang sahabat yang tinggal berdekatan sebagai sahabat akrab dan membuang sekurang-kurangnya tiga sahabat akrab yang tinggal berjauhan. Jadual 1 jelas menunjukkan bahawa pelajar-pelajar ini - sama ada lelaki mahupun perempuan - lebih cenderung untuk membuang nama sahabat akrab yang tinggal berjauhan berbanding dengan sahabat akrab yang tinggal berdekatan. Alvin, Alif, Yana dan Mila telah membuang 3 hingga 9 nama sahabat akrab yang tinggal berjauhan - seperti yang telah disenaraikan dalam peta persahabatan pertama - disebabkan oleh kurangnya interaksi bersama mereka sepanjang tiga minggu penulisan diari persahabatan. Sebaliknya, Ken, Alvin, Yana dan Aina telah menambah satu hingga lima nama sahabat yang tinggal berdekatan dengan mereka dalam peta persahabatan kedua.

Namun, terdapat dua orang pelajar lelaki iaitu Ken dan Alif yang menambah sahabat yang tinggal berjauhan sebagai sahabat akrab, selepas tiga minggu. Walau bagaimanapun, jarak fizikal merupakan sebab utama penambahan ini. Ken telah menambah seorang sahabat yang datang melawatnya di United Kingdom dan menginap sementara di rumahnya selama tiga hari. Walaupun mereka tidak bertemu secara bersemuka setelah berpisah di sekolah menengah, Ken menjadi emosi apabila mengimbau kembali kenangan dan pengalaman yang dikongsi bersama dengan sahabatnya, Lau pada zaman persekolahannya.

Salah seorang rakan sekolah saya di Malaysia datang ke UK sebagai pelajar pertukaran. Kami tidak pernah berjumpa selama tiga atau empat tahun. Dia datang melawat saya dan tinggal di rumah saya untuk tiga hari. Kadangkadang kawan baik adalah seperti ini. Kita tidak berjumpa untuk tempoh masa yang lama, tetapi apabila kita berjumpa, tiada apa yang berubah. Saya menjadi sedikit emosi apabila saya berpisah dengannya sekali lagi. Walaupun kami tidak berjumpa untuk tempoh yang lama, saya menjadi sedikit emosi dan berasa dekat dengannya selepas tinggal bersama dan berkongsi masa yang sama dalam tempoh tiga hari ini (Ken).

Konsep 'kawan fosil' yang dicadangkan oleh Spencer dan Pahl (2006, hlm.74) adalah relevan untuk menggambarkan persahabatan seperti ini. Walaupun Ken dan sahabatnya tidak pernah berhubung dan berinteraksi untuk tempoh masa yang lama, Ken masih dapat merasakan kehadirannya dan mendapati persahabatan akrab mereka diaktifkan semula ketika mereka bertemu di United Kingdom, walaupun hanya untuk beberapa hari. Berkongsi ruang sosial yang sama dan melakukan aktiviti fizikal yang sama mencetuskan kembali nilai intimasi dalam persahabatan mereka. 
Selain daripada Ken, Alif juga berkongsi pandangan yang serupa. Alif telah menambah tiga orang sahabat yang tinggal di bandar yang berbeza di United Kingdom sebagai sahabat akrab. Dalam tempoh masa tiga minggu seperti yang dinyatakan, Alif telah terlibat dalam aktiviti keagamaan di bandar $\mathrm{M}$, iaitu tempat tinggal tiga orang sahabat tersebut. Mereka disenaraikan sebagai sahabat akrab kerana Alif meluangkan banyak masa bersama, tinggal di rumah mereka untuk beberapa hari dan berkongsi masalah peribadinya dengan mereka.

Saya baru sedar yang saya banyak melakukan aktiviti dengan mereka sepanjang tiga minggu yang lalu. Saya berjumpa mereka setiap kali saya pergi ke bandar $M$ dan saya tinggal di rumah mereka kerana kami mempunyai program keagamaan pada hujung minggu itu. Hubungan kami menjadi semakin akrab kerana kami melakukan banyak aktiviti bersama. Saya juga menghadapi banyak masalah selama tiga minggu yang lalu dan saya berkongsi beberapa masalah saya dengan mereka. Bagi saya, ada kecenderungan yang lebih tinggi untuk saya bercakap dan berkongsi masalah saya dengan rakanrakan saya apabila kami bertemu. Disebabkan oleh saya mendapat respons yang baik dari mereka, saya merasa terhubung secara emosional dengan mereka dan cenderung untuk berkongsi lebih banyak perkara dengan mereka (Alif).

Pengkaji mendapati bahawa Ken dan Alif berkongsi corak yang sama untuk penambahan nama baharu sebagai sahabat akrab dan corak ini adalah hasil daripada 'jarak dekat yang sementara'. Dalam konteks ini, pertemuan bersemuka telah mencetuskan perhubungan emosi antara Ken dan Alif dengan sahabat-sahabat mereka dan hubungan bersemuka dilihat mempunyai kesan yang signifikan terhadap amalan intimasi antara pelajar dan sahabat akrab mereka. Konsep 'kebiasaan sebagai satu keluarga' (familiarity as a family) (Pazil, 2019) adalah penting untuk menggambarkan keadaan ini. Walaupun Ken dan Alif hanya tinggal di rumah yang sama dengan rakan-rakan mereka selama beberapa hari, berada di dalam rumah yang sama mencipta kebiasaan seperti keluarga. Rutin harian seperti memasak bersama, makan bersama, menaiki kenderaan awam bersama dan pergi ke program bersama telah mencipta aktiviti, ruang dan masa yang mengingatkan pelajar akan kebiasaan yang sama sewaktu berada bersama keluarga. Kebiasaan dalam amalan keluarga ini menjadikan hubungan persahabatan akrab sama seperti hubungan dalam keluarga. Dalam kes ini, Ken dan Alif bertingkah laku seperti keluarga yang mencetuskan perhubungan emosi dengan sahabat akrab mereka walaupun amalan intimasi ini hanya berlaku selama beberapa hari.

\section{b) Kekerapan Interaksi}

Berdasarkan Jadual 1 di atas, pengkaji mendapati bahawa pelajar lelaki dilaporkan kurang berinteraksi dengan sahabat akrab mereka berbanding dengan pelajar perempuan. Malah, pelajar lelaki lebih kerap berinteraksi dengan sahabat akrab yang tinggal berdekatan berbanding dengan sahabat akrab yang tinggal berjauhan. Dua orang pelajar lelaki iaitu Ken dan Alvin tidak pernah menghubungi mana-mana sahabat akrab yang tinggal berjauhan selama tempoh tiga minggu ini. Manakala, Adam yang sering menghubungi sahabat-sahabat yang tinggal berdekatan seperti yang dilaporkan dalam diari persahabatan, tidak menyenaraikan mereka sebagai sahabat akrab. Sepanjang tempoh tiga minggu tersebut 
Adam hanya berinteraksi dengan dua orang sahabat akrabnya - yang dikenalinya sewaktu di sekolah menengah - yang juga belajar di universiti yang sama dengannya di United Kingdom. Berbeza dengan pelajar-pelajar lelaki, pengkaji mendapati bahawa pelajar-pelajar perempuan lebih kerap berinteraksi dengan sahabat akrab yang tinggal berjauhan, terutamanya ahli keluarga. Walau bagaimanapun, Yana, yang menambah empat nama sahabat yang tinggal berdekatan sebagai sahabat akrab, dilaporkan sering berinteraksi dengan sahabat-sahabat yang baharu dikenali di United Kingdom terutamanya mereka yang juga belajar di universiti yang sama.

Jadual 1 juga menggambarkan bahawa pelajar-pelajar lebih kerap berinteraksi secara bersemuka berbanding dengan secara maya. Malah, pengkaji mendapati bahawa Alvin dan Lily sering memulakan interaksi dengan sahabat akrab yang tinggal berdekatan dengan menggunakan teks mesej menerusi WhatsApp Messenger dan kemudiannya meneruskan interaksi secara bersemuka seperti yang dilaporkan dalam diari persahabatan mereka. Laporan oleh Duggan (2015) menunjukkan bahawa 49 peratus daripada orang muda cenderung untuk menggunakan aplikasi pemesejan seperti WhatsApp Messenger dan iMessage. Selari dengan laporan ini, pengkaji mendapati bahawa aplikasi pemesejan sering digunakan oleh pelajar Malaysia berbanding dengan media sosial yang lain. Aplikasi WhatsApp Messenger membolehkan pengguna untuk menghantar mesej secara percuma tidak seperti khidmat pesanan ringkas (SMS). Malah, sifatnya yang separa-serentak membenarkan penggunanya untuk membentuk dan mengekalkan hubungan persahabatan dan berfikir terlebih dahulu perkara yang ingin dibualkan (Abeele, 2016). Aplikasi mesej ringkas ini juga tidak terhad kepada penggunaan teks sahaja. Pengkaji mendapati bahawa pelajar-pelajar Malaysia ini juga menghantar gambar dan video, menggunakan mesej yang terpadam secara automatik seperti Snapchat, dan aplikasi pemesejan yang dipautkan ke halaman media sosial yang lain untuk perbualan ringkas seperti direct message Instagram dan Facebook Messenger.

Pengkaji juga mendapati bahawa pelajar perempuan sering menghubungi sahabat akrab mereka sekurang-kurangnya sekali dalam tempoh tiga minggu ini, sama ada menerusi panggilan suara atau video. Kekerapan interaksi menerusi panggilan suara ini melibatkan pelajar dengan sahabat akrab yang tinggal berjauhan, kebanyakannya dengan ahli keluarga mereka. Salah seorang pelajar perempuan iaitu Mila lebih kerap membuat panggilan suara dan video dengan sahabat akrabnya yang tinggal berjauhan, terutamanya dengan teman lelakinya yang belajar di Australia. Sebaliknya, pelajar-pelajar lelaki lebih kerap menghantar teks mesej kepada sahabat akrabnya yang tinggal berjauhan, terutamanya ahli keluarga yang berada di Malaysia. Mereka juga jarang menggunakan laman media sosial seperti Facebook dan Instagram untuk berinteraksi dengan sahabat akrab mereka dan tidak merekodkan sebarang interaksi dengan sahabat akrab mereka di laman sosial tersebut. Pelajar-pelajar lelaki menyatakan bahawa mereka kerap memberikan tanda 'suka' (like) dan memberikan komen, namun hanya menganggapnya sebagai aktiviti biasa di media sosial dan tidak cukup intim untuk dicatatkan di dalam diari persahabatan. Namun, tingkah laku ini bagi Boyd (2007) dianggap sebagai 'pemerhati' atau 'penonton yang dapat dilihat' kerana mengetahui mengenai perkembangan sahabat-sahabat mereka di laman sosial walaupun mereka tidak saling menghubungi secara langsung. 
c) Tempoh dan Medium Interaksi

Satu lagi corak interaksi persahabatan akrab yang signifikan dalam kajian ini adalah kebanyakan interaksi berlaku kurang dari satu jam kecuali interaksi bersemuka yang berlangsung selama lebih daripada satu jam, terutamanya dengan sahabat akrab yang tinggal berdekatan. Pengkaji mengkategorikan medium interaksi yang biasanya digunakan oleh pelajar-pelajar Malaysia di United Kingdom untuk berinteraksi dengan sahabat akrab mereka kepada empat jenis medium: 1) muka (interaksi bersemuka), 2) teks (chat, SMS dan Messenger), 3) panggilan (panggilan suara dan video) dan 4) halaman (Facebook dan Instagram). Sandel (2014, hlm.3) berpendapat bahawa pengalaman menjadi pelajar antarabangsa yang tinggal jauh dari rumah adalah berbeza secara kualitinya hari ini berbanding dengan sebelum ini. Perubahan dan perkembangan teknologi daripada mesej berasaskan teks seperti e-mel, pemesejan segera dan menghantar mesej teks ke laman web sosial, imej visual dan video streaming seperti Facebook dan Skype, internet telefon pintar telah mengurangkan "persepsi jarak" (Sandel 2014, hlm.3) dan memudahkan pelajar-pelajar antarabangsa sentiasa mengetahui perkembangan terkini mengenai keluarga dan sahabatsahabat yang berada jauh dari mereka. Penciptaan profil peribadi di laman media sosial, seperti Facebook, Instagram dan Twitter membantu menghubungkan penggguna di seluruh dunia, menjadi platform untuk interaksi sosial dan membenarkan ekspresi maklumat peribadi, seperti jantina, minat, pendidikan dan lokasi (Lambert, 2013).

\section{d) Kandungan Interaksi}

Semasa fasa kedua pengumpulan data, majoriti pelajar sedang sibuk dengan penghantaran kerja kursus dan ujian serta bersedia untuk permulaan semester baharu. Hal ini menyebabkan mereka terpaksa membahagikan masa yang terluang untuk menghubungi sahabat akrab mereka terutamanya yang tinggal berjauhan. Pengkaji mendapati bahawa kebanyakan interaksi yang direkodkan dimulakan oleh sahabat akrab bukannya pelajar. Sebahagian besar interaksi yang direkodkan adalah mengenai kehidupan harian dan perkara yang berlaku di universiti, terutamanya bersama dengan sahabat akrab yang tinggal berdekatan. Selain itu, sahabat akrab yang tinggal berdekatan juga dihubungi untuk sokongan dan bantuan fizikal. Sebaliknya, interaksi antara pelajar dengan sahabat akrab yang tinggal berjauhan adalah lebih kepada mengetahui perkembangan kehidupan masingmasing serta berkongsi mengenai pelan bercuti dan masa depan.

Walaupun tempoh tiga minggu ini tidak dapat menggambarkan amalan intimasi pelajar dan sahabat akrab mereka dengan sepenuhnya, pengkaji mendapati bahawa terdapat perbezaan yang signifikan antara pelajar lelaki dan pelajar perempuan. Pelajar perempuan cenderung untuk merindui serta berkongsi perasaan dan emosi dengan sahabat akrab mereka berbanding dengan pelajar lelaki. Pelajar perempuan juga dilaporkan sering bertanya kepada sahabat akrab mereka, terutamanya ahli keluarga yang berada di Malaysia, mengenai keadaan kesihatan dan kesejahteraan mereka berbanding dengan pelajar lelaki. Malah, pelajar perempuan bukan sahaja menyenaraikan lebih banyak nama ahli keluarga mereka tetapi juga lebih kerap berhubung dengan mereka. Pengkaji mendapati bahawa pelajar perempuan menghubungi ahli keluarga mereka sekurang-kurangnya satu kali seminggu dan kerap menghantar mesej kepada mereka melalui grup sembang di WhatsApp Messenger. 
Berdasarkan dapatan ini, pengkaji mendapati bahawa pelajar perempuan lebih berusaha untuk memulakan perbualan dengan sahabat akrab mereka, sama ada yang tinggal berjauhan mahupun yang tinggal berdekatan dengan mereka, dan mempunyai interaksi yang kerap walaupun mereka sibuk dengan jadual sebagai pelajar universiti. Pengkaji bersetuju dengan hujah Felmlee et al. (2012) bahawa pelajar perempuan memberikan nilai yang lebih tinggi untuk menghubungi sahabat akrab mereka dan menghargai keakraban perhubungan mereka berbanding dengan pelajar lelaki. Perbezaan gender ini dilihat penting kerana wanita sering dikaitkan dengan penjagaan berbanding dengan lelaki (Morgan, 2011). Pelajar perempuan dilihat lebih prihatin kerana mereka selalu memulakan perbualan dengan ahli keluarga dan sahabat akrab mereka untuk mengetahui perkembangan kehidupan dan kesejahteraan. Walau bagaimanapun, zon waktu yang berbeza mempengaruhi kekerapan interaksi dan juga media yang digunakan.

\section{KESIMPULAN}

Mobiliti sementara ke luar negara dilihat mempunyai kesan yang besar terhadap cara pelajar Malaysia mengamalkan intimasi dengan sahabat akrab mereka, sama ada yang tinggal berjauhan mahupun yang tinggal berdekatan dengan mereka. Empat corak interaksi yang telah dikenal pasti dalam kajian ini iaitu 1) penambahan atau penyingkiran nama sahabat akrab, 2) kekerapan hubungan, 3) tempoh dan medium interaksi dan 4) kandungan interaksi telah menunjukkan perbezaan yang ketara dalam persahabatan akrab pelajar Malaysia di United Kingdom. Antaranya adalah perbezaan gender dalam corak interaksi dengan sahabat akrab dan juga perbezaan corak interaksi dengan sahabat akrab yang tinggal berjauhan dan sahabat akrab yang tinggal berdekatan. Pelajar perempuan lebih kerap berinteraksi dan memulakan interaksi dengan sahabat akrab berbanding pelajar lelaki dan pelajar-pelajar ini lebih kerap berinteraksi dengan sahabat akrab yang tinggal berjauhan dan sahabat akrab yang tinggal berdekatan. Media sosial menjadi platform utama untuk mendekatkan jarak fizikal antara pelajar dan sahabat akrab mereka di Malaysia. Malah, media sosial juga menjadi platform untuk pelajar Malaysia di United Kingdom untuk memulakan interaksi bersemuka dengan sahabat akrab yang tinggal di negara yang sama. Oleh itu, media sosial sangat signifikan dalam membantu untuk mengukuhkan amalan intimasi dalam persahabatan akrab sama ada sahabat akrab yang tinggal berjauhan mahupun yang tinggal berdekatan dengan pelajar Malaysia di United Kingdom.

\section{BIODATA}

Nur Hafeeza Binti Ahmad Pazil, pensyarah kanan dalam bidang sosiologi di Pusat Pengajian Sains Kemasyarakatan, Universiti Sains Malaysia. Bidang kepakaran beliau ialah persahabatan, intimasi dan hubungan personal, mobiliti sosial, pelajar antarabangsa dan media sosial. E-mel: hafeezapazil@usm.my 


\section{RUJUKAN}

Abdul Latiff Ahmad, Emma Mirza Wati Mohamad, Latiffah Pawanteh, Ali Salman, \& Rusyda Helma Mohd. (2014). Adaptation and the new media technology: A study on Malaysian students in Australia and United Kingdom. Jurnal Komunikasi: Malaysian Journal of Communication, 30(1), 195-206.

Abeele, V. M. M. (2016). Mobile lifestyles: Conceptualizing heterogeneity in mobile youth culture. New Media \& Society, 18(6), 908-926.

Ali Salman, \& Siti Minanda Pulungan. (2017). Pendedahan diri, motivasi dan kepuasan penggunaan Facebook dalam menjalin persahabatan. Jurnal Komunikasi: Malayasian Journal of Communication, 33 (1), 438-459.

Boyd, D. (2007). Social network sites: Public, private, or what?. Knowledge Tree, 13, 1-7.

Brickell, C. (2012). Sexuality, power and the sociology of the internet. Current Sociology, 60(1), 28-44.

Boyd, D. (2010). Friendship. Dalam M. Ito, S. Baumer, M. Bittanti, D. Boyd, R. Cody, B. H. Stephenson, ..., \& L. Tripp (Eds.), Hanging out, messing around, geeking out: Living and learning with new media (pp. 79-115). Cambridge, Massachusetts: The MIT Press.

Cantó-Milà, N., Núñez-Mosteo, F., \& Seebach, S. (2016). Between reality and imagination, between you and me: Emotions and daydreaming in times of electronic communication. New Media \& Society, 18(10), 2395-2412.

Chambers, D. (2013). Social media and personal relationships: Online intimacies and networked friendship. United Kingdom: Palgrave Macmillan.

Cronin, A. M. (2014, September). Distant friends, mobility and sensed intimacy. Mobilities, 1-19.

Davies, K. (2011). Friendship and personal life. In V. May (Ed.), Sociology of personal life (pp. 72-84). Basingstoke: Palgrave Macmillan.

Duggan, M. (2015, August 19). Mobile messaging and social media 2015. Pew Research Centre: Internet \& Technology. Retreived from https://www.pewresearch.org/internet/2015/08/19/mobile-messaging-and-socialmedia-2015/

Felmlee, D., Sweet, E., \& Sinclair, H.C. (2012). Gender rules: Same- and cross-gender friendships norms. Sex Roles, 66(7-8), 518-529.

Hall, J. A., \& Baym, N. K. (2011). Calling and texting (too much): Mobile maintenance expectations, (over)dependence, entrapment, and friendship satisfaction. New Media \& Society, 14(2), 316-331.

Holmes, M. (2011). Emotional reflexivity in contemporary friendships: Understanding it using elias and Facebook etiquette. Sociological Research Online, 16(1), 11-23.

Jamieson, L. (2013). Personal relationships, intimacy and the self in a mediated and global digital age. Dalam K. Orton-johnson \& N. Prior (Eds.), Digital sociology: Critical perspectives (pp. 13-28). London, UK: Palgrave Macmillan.

Jamilah Maliki, Normah Mustaffa, \& Mohd. Nor Shahizan Ali. (2019). Konstruksi identiti dalam talian dari perspektif pengguna Facebook. Jurnal Komunikasi: Malaysian Journal of Communication, 35(4), 119-134.

Jurkane-Hobein, I. (2015). Imagining the absent partner: Intimacy and imagination in longdistance relationships. Innovative Issues and Approaches in Social Sciences, 8(1), 223241. 
Lambert, A. (2013). Intimacy and friendship on Facebook. London, UK: Palgrave Macmillan.

McLaughlin, C. \& Vitak, J. (2011). Norm evolution and violation on Facebook. New Media \& Society, 14(2), 299-315.

Morgan, D. (2011). Locating "family practices". Sociological Research Online, 16(4), 1-9.

Pahl, R. (2000). On friendship. Cambridge: Polity Press.

Sandel, T. L. (2014). “Oh, I'm Here!": Social media's impact on the cross-cultural adaptation of students studying abroad. Journal of Intercultural Communication Research, 43(1), 1-29.

Siti Ezaleila Mustafa. (2016). Penggunaan laman sosial dan impaknya terhadap hubungan persahabatan dalam talian. Jurnal Komunikasi: Malaysian Journal of Communication, 32(2), 65-81.

Spencer, L., \& Pahl, R. (2006). Rethinking friendship: Hidden solidarities today. Princeton \& Oxford: Princeton University Press.

Office for National Statistics. (2017). Population of the UK by country of birth and nationality. Retrieved from https://www.ons.gov.uk/peoplepopulationandcommunity/ populationandmigration/internationalmigration/datasets/populationoftheunitedking dombycountryofbirthandnationality

Pazil, N. H. A. (2019). Familiarity as a family: Close friendships between malaysian students and their co-national friends in the UK. Journal of International Students, 9(3), 896911.

Policarpo, V. (2016). "The real deal": Managing intimacy within friendship at a distance. Qualitative Sociology Review, XII(2), 22-42.

Taylor, A. S., \& Harper, R. (2003). The gift of the gab?: A design oriented sociology of young people's use of mobiles. Computer Supported Cooperative Work (CSCW), 12(3), 267296.

The UK Council for International Student Affairs (UKCISA). (2019). International student statistics: UK higher education. Retrieved from https://www.ukcisa.org.uk/Research-Policy/Statistics/International-student-statistics-UK-higher-education 